\title{
Brassinosteroids and Response of Plants to Heavy Metals Action
}

\author{
Iwona Rajewska, Marta Talarek and Andrzej Bajguz* \\ Faculty of Biology and Chemistry, Institute of Biology, University of Białystok, Bialystok, Poland
}

Brassinosteroids (BRs) are a widespread group of plant hormones. These phytohormones play a crucial role in the regulation of growth and development of various plant species, and they demonstrate high biological activity. BRs are considered to demonstrate protective activity in the plants exposed to various stresses. Due to rapid industrialization and urbanization, heavy metals have become one of the most important plant stressors. In plants, accumulation of heavy metals beyond the critical levels leads to oxidative stress. However, BRs may inhibit the degradation of lipids, resulted from the overproduction of reactive oxygen species under stress conditions, and increase the activity of antioxidants. They also have the ability to promote phytochelatins synthesis.

Keywords: antioxidants, brassinosteroids, heavy metals, phytochelatins, phytohormones

\section{OPEN ACCESS}

Edited by:

Vijay Pratap Singh,

Ramanuj Pratap Singhdev Post

Graduate College, India

Reviewed by:

Durgesh Kumar Tripathi,

Banaras Hindu University, India

Rakesh Kumar Shukla,

Central Institute of Medicinal

and Aromatic Plants, India

${ }^{*}$ Correspondence:

Andrzej Bajguz

abajguz@uwb.edu.pl

Specialty section:

This article was submitted to

Plant Physiology,

a section of the journal

Frontiers in Plant Science

Received: 17 March 2016

Accepted: 25 April 2016

Published: 09 May 2016

Citation:

Rajewska I, TalarekM and BajguzA (2016) Brassinosteroids

and Response of Plants to Heavy

Metals Action. Front. Plant Sci. 7:629.

doi: 10.3389/fpls.2016.00629

\section{INTRODUCTION}

Brassinosteroids (BRs) are plant hormones that belong to the class of polyhydroxy steroids. BRs can regulate multiple physiological functions, such as embryogenesis and seed germination, cell divisions and elongation, development of thecae, microspore germination and growth of pollen tubes, differentiation of tracheal elements, polarization of cellular membranes as well as leaf senescence and dying (Clouse and Sasse, 1998). For the past one decade, there has been a significant progress in our understandings' of BRs biosynthesis, degradation, and their signaling, as well as their versatile role in growth and developmental processes in plants (Bajguz, 2007, 2012; Zhao and Li, 2012; Wang et al., 2014; Zhabinskii et al., 2015).

This paper highlights the progress in the field of BRs research with more emphasis on new key players identified in the growing implications of BRs research in the tolerance of metal stress.

\section{BRASSINOSTEROIDS VS. HEAVY METAL STRESS}

Industrial revolution and the activity of man lead to more and more serious pollution of the environment with metals. They finally get infiltrated in the food chain, which results into the degradation of ecosystem. Plants have the amazing ability to take up and accumulate metals from the environment. Although some metals are essential for most redox reactions fundamental for cellular functions, still, high concentrations of all metals, even those essential for plant growth and metabolism, cause toxic effects. The impact of toxic metals on plants mostly involves interaction with functional groups of molecules in cells, particularly proteins, and polynucleotides (Chary et al., 2008). These effects may include growth inhibition, the reduction in net photosynthetic rate, lowering the contents of photosynthetic pigments, carbohydrates and proline, increased content of malondialdehyde. During oxidative stress, several plant hormones play a key role. BRs, however, not only regulate different physiological and morphogenetic responses in plants but also help 
in reducing various biotic and abiotic stresses (Krishna, 2003; Bajguz and Hayat, 2009; Vardhini, 2016).

\section{BRs RESPONSE TO PLANT DEVELOPMENT}

Accumulation of metals such as cadmium, copper, lead, and zinc after the application of BRs has been investigated in different cultivated plants, e.g., tomato, barley, and radish (Anuradha and Rao, 2007a,b; Hayat et al., 2010; Hasan et al., 2011; Ramakrishna and Rao, 2013, 2015). It has been also proved that after the application of 24-epibrassinolide (EBL, one of the BRs) the lead content in a beet root is even $50 \%$ lower than in plants treated with metal alone, since this hormone considerably reduces the absorption of this metal (Khripach et al., 1999). When using BRs for Indian mustard (Brassica juncea) seeds before the germination and then exposing them against copper stress, reduced uptake and accumulation of copper was observed, as well as improvement in shoot generation and biomass production also occurred (Sharma et al., 2007). Changes in the content of ions/metals under the influence of BRs depend on the stage of development during which they were applied to the plant. Research conducted so far shows that cultures of Chlorella vulgaris treated with metals and BRs display lower bioaccumulation of metals than those which were only exposed to metals. After reducing the accumulation of metals, BRs stimulate the growth, and development of C. vulgaris. The culture of C. vulgaris exposed to metals shows that BRs prevent the loss of chlorophyll, sugar, and protein and improve the syntheses of phytochelatins (PC; Bajguz, 2000, 2002). Moreover, it has been proved that brassinolide promotes the growth of mung bean seedlings under aluminum stress (Abdullahi et al., 2003). In addition, EBL considerably increases the fresh mass of shoots and roots as well as chlorophyll content in mung beans under aluminum stress (Ali et al., 2008a). We also know that the use of 28-homobrassinolide (HBL) in Indian mustard exposed to nickel activity improves seed germination as well as the lengths of shoots and roots, both under Ni stress and otherwise (Yusuf et al., 2011). BR eliminates the toxic effect of cadmium on photochemical pathways in rape cotyledons, mostly by means of alleviating the damage to reaction centers and $\mathrm{O}_{2}$ evolving complexes and by ensuring efficient electron transport (Janeczko et al., 2005).

Recent studies show that HBL can reduce metal stress in plants, such as Indian mustard, radish, wheat, and maize (Anuradha and Rao, 2007b; Bhardwaj et al., 2007; Hayat et al., 2007; Sharma et al., 2010). It is also known that HBL regulates the activities of various enzymes involved in photosynthesis and plant defense mechanisms in wheat and Indian mustard exposed to different abiotic stresses (Hayat et al., 2007). It has been revealed that pre-soaked seeds in HBL improves seedling growth as well as chlorophyll $a$ content under the exposure of metal. Moreover, it has been shown that the increased uptake of $\mathrm{Cr}^{2+}$ in radish or rice seedlings lowers considerably after treatment with BR, thus reducing chromium toxicity (Sharma et al., 2011, 2016).

\section{REACTIVE OXYGEN SPECIES AND ANTIOXIDANTS}

Quick development of industry and the resultant more and more serious pollution of the environment with metals has been the reason for extensive investigation of potential mechanisms of adaptation to this stressor. Negative effects of metals on plants are first of all manifested in growth inhibition. The basic toxic activity of metal ions results from oxidative stress, related with generating reactive oxygen species (ROS; Krishna, 2003). In response to metal stress, calcium-dependent protein kinases, calmodulins, calmodulin-like proteins, and calcineurin B-like proteins are also activated as important $\mathrm{Ca}^{2+}$ sensors in plants (Ludwig et al., 2004). Experiments carried out with the use of Arabidopsis have shown that in response to $\mathrm{Cd}$, two mitogen-activated protein kinases (MAPKs), MPK3 and MPK6 are triggered as a result of ROS accumulation (Liu et al., 2010) (Figure 1). However, to this date there is no evidence on direct association or interaction with BRs. Toxicity related with metal activity leads to overproduction of ROS and thus causes oxidative damage resulting in membrane destruction, which in turn affects the levels of antioxidants and metallozymes or antioxidant enzymes (Pandey et al., 2005). Experiments conducted by Ali et al. (2008b) using mustard plants show that the influence of BR on the antioxidative system is more evident under stress conditions, suggesting that an elevated level of antioxidative system partially increases the plants' tolerance to salt and/or nickel stress and thus protects the photosynthesis and plant growth. The activities of catalase (CAT), ascorbate peroxidise (APOX), and superoxide dismutase (SOD), as well as the content of proline, increased in cadmium-treated plants, especially in mustard plants simultaneously supplemented with HBL. Similar results were obtained for mung bean plants exposed to aluminum with the simultaneous spraying of EBL or HBL. Spraying the leaves with BRs significantly enhanced the contents of antioxidant enzymes and proline in aluminumstressed mung bean seedlings (Ali et al., 2008a). Other reports have also showed that BR application can modify the activity of antioxidant enzymes in maize, mustard, radish, wheat, and rice exposed to metal stress (Sharma et al., 2007, 2010, 2016). According to the AsA-GSH Cycle/Asada Halliwell Pathway ascorbate is essential for ROS scavenging. Its cellular pool is maintained stable by dehydroascorbate reductase (DHAR) and monodehydroascorbate reductase (MDHAR) with NADPH as the reducing power. This may lead to the alteration of redox potential of cells, and consequently membrane destabilization under stress (Noctor and Foyer, 1998; Mittler, 2002). BRs probably maintain the modified cell redox state by regulating activities of SOD, CAT, APOX, glutathione reductase (GR), DHAR, and MDHAR. The redox potential can be re-established by the means of reducing phospholipid peroxidation in cell membranes or by the accumulation of certain osmoprotectant, e.g., proline (Figure 1). Fariduddin et al. (2009) reported that the content of proline and antioxidative enzymes increased in response to copper stress, and this effect became even stronger after the application of HBL. Furthermore, BRs can modulate the activity of proteins and other enzymes in the membrane, either influencing protein conformation or protein activity by 


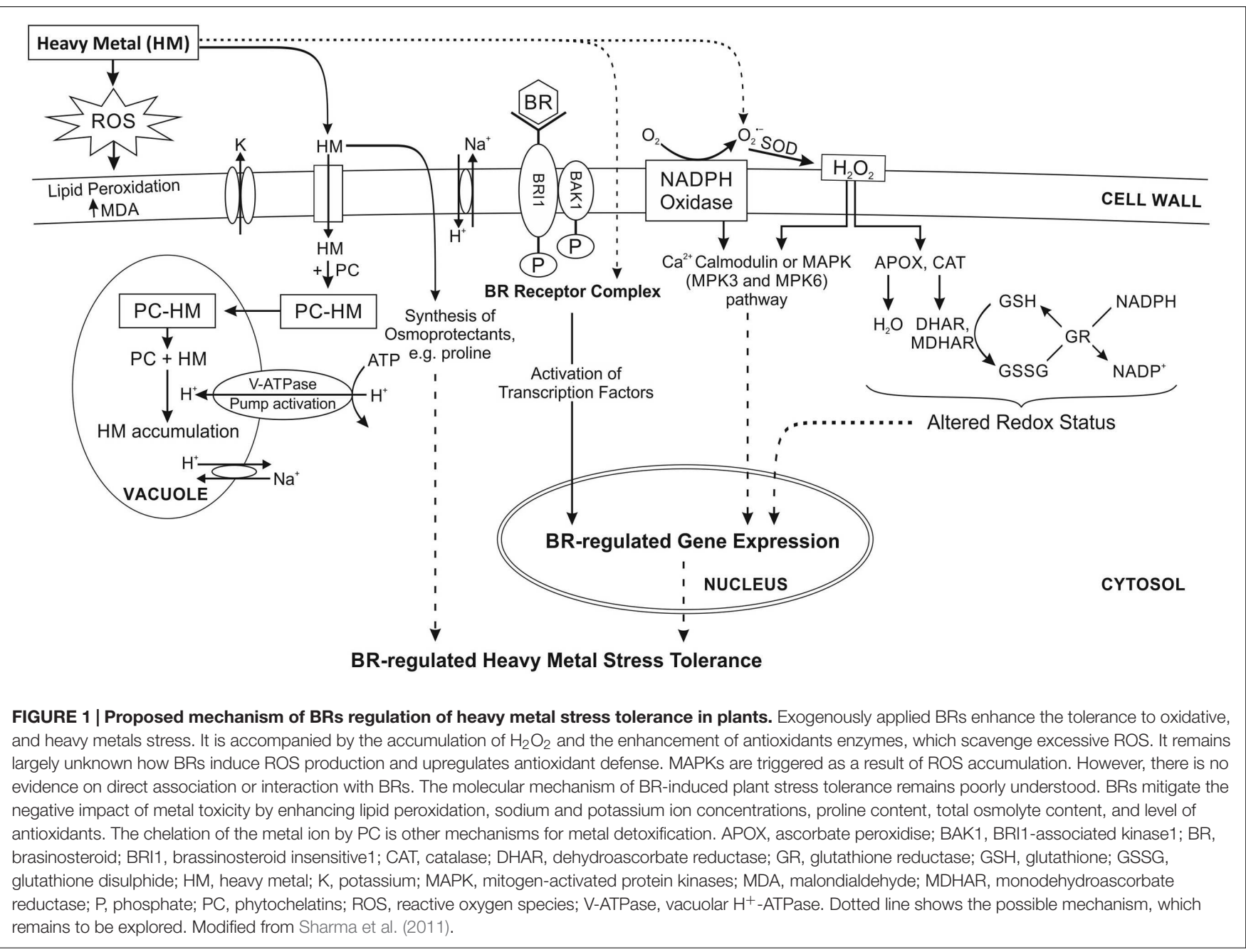

direct interactions of proteins and sterols (Lindsey et al., 2003). It is known that BRs are recognized by a protein complex that includes the leucine-rich repeat receptor-like kinase encodes by BRI1. BRI1 can receive peptide signals, thus serving the protective role (Wang et al., 2014). At the occurrence of stress, these signals may regulate defense responses. Different BR-regulated genes participate in the response to stress and may encode PC (Figure 1), osmolytes, organic acids, metallothioneins, and stress protective proteins such as heat-shock proteins (Gendron and Wang, 2007).

Brassinosteroids may inhibit the degradation of lipids resulting from the overproduction of ROS under metal stress, and stimulate the activity of antioxidative enzymes (Figure 1) (Sudo et al., 2008; Soares et al., 2016). Other studies show that increased expression of GR, DHAR, and MDHAR is observed in plants exposed to chromium combined with $\mathrm{HBL}$, which improves their tolerance to oxidative stress caused by this metal. The modified activity of antioxidant enzymes may suggest that HBL treated seedlings were affected by chromium to a lesser extent than those which have not been supplemented with HBL (Sharma et al., 2011). It has also been proved that in B. juncea arsenicrelated stress causes the activation of antioxidative enzymes and synthesis of BRs, which may be one of plants' strategies of protection from stress. Synthesis of BRs is either an example of direct impact of metal stress or a response of $B$. juncea plants to the stress, aimed at alleviating its effects (Kanwar et al., 2015).

\section{PHYTOCHELATINS SYNTHESIS}

The syntheses of PC are one of the mechanism of metal detoxification in plants. PC are metal-binding cysteine-rich compounds, which facilitate the chelation of metal ions in cytosol or their compartmentalization in vacuoles (Figure 1). Their general structure is $(\gamma \text {-Glu-Cys })_{n}$-Gly, where $n$ can be as high as 11 , but it is usually in the range of $2-5$. These metalbinding peptides are derived from glutathione. BRs are known to stimulate the syntheses of PC in cells treated with lead (Bajguz, 2002).

\section{BIOSORPTION}

Biosorption is another mechanism used by plants to remove metals, independent of cell metabolism. Binding metal ions 
may occur through the mechanism of physical adsorption, ion exchange, chemical sorption, complexation, or chelatation. The metal ions are adsorbed by biosorbents as a result of their interactions with functional (carboxyl, hydroxyl, amino, phosphoryl, etc.) groups present on the surface of the biosorbent's cell wall. Research on the usefulness of sorption in removing metal ions from water solutions proves that the $\mathrm{pH}$ of the solution is particularly important for the process. The optimum $\mathrm{pH}$ of metal ions sorption for most of the natural sorbents is within the range of 4-6 (Han et al., 2005; Gupta et al., 2009). Lowering the $\mathrm{pH}$ in cell wall spaces stimulates the growth of $C$. vulgaris under the influence of BRs. The impact of BRs on proton excretion is related to early hyperpolarization of transmembrane electrical potential. Proton excretion caused by these hormones is additionally stimulated by the presence of $\mathrm{K}^{+}$in the substrate (Bajguz, 2002).

\section{CONCLUSION}

Plants under various stresses, both biotic and abiotic ones, generate large amounts of ROS which may oxidize lipids, proteins, and nucleic acids, resulting in disturbances at the cellular level which lead to apoptosis. The toxic influence of metals on plants also depends on its absorption and bioaccumulation, which in turn is associated with the bioavailability, uptake route, storage, degradation, immobilization, and excretion of the metal, as well as avoidance/tolerance mechanisms. Studies concerning the molecular mechanism of BRs' activity will allow for better and more thorough understanding of anti-stress activities of these phytohormones and facilitate the development of appropriate strategies of protecting plants from metal stress. BR signal transduction may result in activation of $\mathrm{NADPH}$ oxidase to ROS production, which probably initiates a cascade of protein phosphorylation through MAPKs to activate transcription

\section{REFERENCES}

Abdullahi, B. A., Gu, X.-G., Gan, Q.-L., and Yang, Y.-H. (2003). Brassinolide amelioration of aluminium toxicity in mung bean seedling growth. J. Plant Nutr. 26, 1725-1734. doi: 10.1081/PLN-120023278

Ali, B., Hasan, S. A., Hayat, S., Hayat, Q., Yadav, S., Fariduddin, Q., et al. (2008a). A role for brassinosteroids in the amelioration of aluminum stress through antioxidant system in mung bean (Vigna radiata L. Wilczek). Environ. Exp. Bot. 62, 153-159. doi: 10.1016/j.envexpbot.2007.07.014

Ali, B., Hayat, S., Fariduddin, Q., and Ahmad, A. (2008b). 24-Epibrassinolide protects against the stress generated by salinity and nickel in Brassica juncea. Chemosphere 72, 1387-1392. doi: 10.1016/j.chemosphere.2008. 04.012

Anuradha, S., and Rao, S. S. R. (2007a). Effect of 24-epibrassinolide on the growth and antioxidant enzyme activities in radish seedlings under lead toxicity. Indian J. Plant Physiol. 12, 396-400.

Anuradha, S., and Rao, S. S. R. (2007b). The effect of brassinosteroids on radish (Raphanus sativus L.) seedlings growing under cadmium stress. Plant Soil Environ. 5, 465-472.

Bajguz, A. (2000). Blockade of heavy metals accumulation in Chlorella vulgaris cells by 24-epibrassinolide. Plant Physiol. Biochem. 38, 797-801. doi: 10.1016/S09819428(00)01185-2 factors to target specific genes participating in cellular protection (Xia et al., 2009). Owing to the importance of BRs in the crop improvement, further investigations are needed to identify the key regulatory elements in BR signaling pathway and the underlying mechanism of BR-modulated growth and developmental responses in major crop plants to design optimal strategies to enhance crop yield and improve their performance under stress conditions.

\section{PERSPECTIVES}

Care about the environment and the necessity to restore its original properties forces people to seek new, alternative ways of cleaning the environment. A cheap and promising way of solving ecological problems is phytoremediation. Assisted phytoremediation is based on chemical additives to soil, such as chelators, organic acids, etc., which improve the bioavailability of metals for plant uptake. Some recent studies are focused on the use of phytohormones as plant additives for phytoremediation purposes (Barbafieri and Tassi, 2011). Because BRs can modify some agronomic traits of plants, the application of these phytohormones in phytoremediation is a desired subject of study.

\section{AUTHOR CONTRIBUTIONS}

IR and MT contributed to the writing of the manuscript. AB participated in drawing Figure $\mathbf{1}$ and in critically revising the manuscript.

\section{ACKNOWLEDGMENT}

This project has been financed from the funds of the National Science Centre allocated on the basis of the decision number DEC-2012/05/B/NZ8/00958.

Bajguz, A. (2002). Brassinosteroids and lead as stimulators of phytochelatins synthesis in Chlorella vulgaris. J. Plant Physiol. 159, 321-324. doi: 10.1078/01761617-00654

Bajguz, A. (2007). Metabolism of brassinosteroids in plants. Plant Physiol. Biochem. 45, 95-107. doi: 10.1016/j.plaphy.2007.01.002

Bajguz, A. (2012). "Origin of brassinosteroids and their role in oxidative stress in plants," in Phytohormones and Abiotic Stress Tolerance in Plants, eds N. A. Khan, R. Nazar, N. Iqbal, and N. A. Anjum (Berlin: Springer-Verlag), 169-183.

Bajguz, A., and Hayat, S. (2009). Effects of brassinosteroids on the plant responses to environmental stresses. Plant Physiol. Biochem. 47, 1-8. doi: 10.1016/j.plaphy.2008.10.002

Barbafieri, M., and Tassi, E. (2011). "Brassinosteroids for phytoremediation application," in Brassinosteroids: a Class of Plant Hormone, eds S. Hayat and A. Ahmad (Dordrecht: Springer), 403-438.

Bhardwaj, R., Arora, N., Sharma, P., and Arora, H. K. (2007). Effects of 28homobrassinolide on seedling growth, lipid peroxidation and antioxidative enzyme activities under nickel stress in seedlings of Zea mays L. Asian J. Plant Sci. 6, 765-772. doi: 10.3923/ajps.2007.765.772

Chary, N. S., Kamala, C. T., and Raj, D. S. (2008). Assessing risk of heavy metals from consuming food grown on sewage irrigated soils and food chain transfer. Ecotoxicol. Environ. Saf. 69, 513-524. doi: 10.1016/j.ecoenv.2007.04.013 
Clouse, S. D., and Sasse, J. M. (1998). Brassinosteroids: essential regulators of plant growth and development. Annu. Rev. Plant Physiol. Plant Mol. Biol. 49, 427-451. doi: 10.1146/annurev.arplant.49.1.427

Fariduddin, Q., Khanam, S., Hasan, S. A., Ali, B., Hayat, S., and Ahmad, A. (2009). Effect of 28-homobrassinolide on the drought stress-induced changes in photosynthesis and antioxidant system of Brassica juncea L. Acta Physiol. Plant. 31, 889-897. doi: 10.1007/s11738-009-0302-7

Gendron, J. M., and Wang, Z. Y. (2007). Multiple mechanisms modulate brassinosteroid signaling. Curr. Opin. Plant Biol. 10, 436-441. doi: 10.1016/j.pbi.2007.08.015

Gupta, S., Kumar, D., and Gaur, J. P. (2009). Kinetic and isotherm modeling of lead(II) sorption onto some waste plant materials. Chem. Eng. J. 148, 226-233. doi: 10.1016/j.cej.2008.08.019

Han, R., Zhang, J., Zou, W., Shi, J., and Liu, H. (2005). Equilibrium biosorption isotherm for lead ion on chaff. J. Hazard Mater. 125, 266-271. doi: 10.1016/j.jhazmat.2005.05.031

Hasan, S. A., Hayat, S., and Ahmad, A. (2011). Brassinosteroids protect photosynthetic machinery against the cadmium induced oxidative stress in two tomato cultivars. Chemosphere 84, 1446-1451. doi: 10.1016/j.chemosphere.2011.04.047

Hayat, S., Ali, B., Hassan, S. A., and Ahmad, A. (2007). Brassinosteroid enhanced the level of antioxidants under cadmium stress in Brassica juncea. Environ. Exp. Bot. 60, 33-41. doi: 10.1016/j.envexpbot.2006.06.002

Hayat, S., Hasan, S. A., Hayat, Q., and Ahmad, A. (2010). Brassinosteroids protect Lycopersicon esculentum from cadmium toxicity applied as shotgun approach. Protoplasma 239, 3-14. doi: 10.1007/s00709-009-0075-2

Janeczko, A., Koscielniak, J., Pilipowicz, M., Szarek-Lukaszewska, G., and Skoczowski, A. (2005). Protection of winter rape photosystem 2 by 24 epibrassinolide under cadmium stress. Photosynthetica 43, 293-298. doi: 10.1007/s11099-005-0048-4

Kanwar, M. K., Poonam, and Bhardwaj, R. (2015). Arsenic inducted modulation of antioxidative defense system and brassinosteroids in Brassica juncea. L. Ecotox. Environ. Safe 115, 119-125. doi: 10.1016/j.ecoenv.2015. 02.016

Khripach, V. A., Zhabinskii, V. N., and De Groot, A. E. (1999). Brassinosteroids. A New Class of Plant Hormones. San Diego: Academic Press.

Krishna, P. (2003). Brassinosteroids-mediated stress responses. J. Plant Growth Regul. 22, 289-297. doi: 10.1007/s00344-003-0058-z

Lindsey, K., Pullen, M. L., and Topping, J. F. (2003). Importance of plant sterols in pattern formation and hormone signaling. Trends Plant Sci. 8, 521-525. doi: 10.1016/j.tplants.2003.09.012

Liu, X.-M., Kim, K. E., Kim, K.-C., Nguyen, X. C., Han, H. J., Jung, M. S., et al. (2010). Cadmium activates Arabidopsis MPK3 and MPK6 via accumulation of reactive oxygen species. Phytochemistry 71, 614-618. doi: 10.1016/j.phytochem.2010.01.005

Ludwig, A. A., Romeis, T., and Jones, J. D. G. (2004). CDPK-mediated signaling pathways: specificity and cross-talk. J. Exp. Bot. 55, 181-188. doi: $10.1093 / \mathrm{jxb} / \mathrm{erh} 008$

Mittler, R. (2002). Oxidative stress, antioxidants and stress tolerance. Trends Plant Sci. 7, 405-410. doi: 10.1016/S1360-1385(02)02312-9

Noctor, G., and Foyer, C. H. (1998). Ascorbate and glutathione: keeping active oxygen under control. Annu. Rev. Plant Physiol. Plant Mol. Biol. 49, 249-279. doi: 10.1146/annurev.arplant.49.1.249

Pandey, V., Dixit, V., and Shyam, R. (2005). Antioxidative responses in relation to growth of mustard (Brassica juncea c.v. Pusa Jaikisan) plants exposed to hexavalent chromium. Chemosphere 61, 40-47. doi: 10.1016/j.chemosphere.2005.03.026
Ramakrishna, B., and Rao, S. S. R. (2013). Preliminary studies on the involvement of glutathione metabolism and redox status against zinc toxicity in radish seedlings by 28 -homobrassinolide. Environ. Exp. Bot. 96, 52-58. doi: 10.1016/j.envexpbot.2013.08.003

Ramakrishna, B., and Rao, S. S. R. (2015). Foliar application of brassinosteroids alleviates adverse effects of zinc toxicity in radish (Raphanus sativus L.) plants. Protoplasma 252, 665-667. doi: 10.1007/s00709-014-0714-0

Sharma, I., Pati, P. K., and Bhardwaj, R. (2010). Regulation of growth and antioxidant enzyme activities by 28 -homobrassinolide in seedlings of Raphanus sativus L. under cadmium stress. Indian J. Biochem. Biophys. 47, 172-177.

Sharma, I., Pati, P. K., and Bhardwaj, R. (2011). Effect of 28-homobrassinolide on antioxidant defence system in Raphanus sativus L. under chromium toxicity. Ecotoxicology 20, 862-874. doi: 10.1007/s10646-011-0650-0

Sharma, P., Bhardwaj, R., Arora, N., and Arora, H. K. (2007). Effect of 28homobrassinolide on growth, zinc metal uptake and antioxidative enzyme activities in Brassica juncea L. seedlings. Braz. J. Plant Physiol. 19, 203-210. doi: 10.1590/S1677-04202007000300004

Sharma, P., Kumar, A., and Bhardwaj, R. (2016). Plant steroidal hormone epibrassinolide regulate - Heavy metal stress tolerance in Oryza sativa L. by modulating antioxidant defense expression. Environ. Exp. Bot. 122, 1-9. doi: 10.1016/j.envexpbot.2015.08.005

Soares, C., de Sousa, A., Pinto, A., Azenha, M., Teixeira, J., Azevedo, R. A., et al. (2016). Effect of 24-epibrassinolide on ROS content, antioxidant system, lipid peroxidation and Ni uptake in Solanum nigrum L. under Ni stress. Environ. Exp. Bot. 122, 115-125. doi: 10.1016/j.envexpbot.2015.09.010

Sudo, E., Itouga, M., Yoshida-Hatanaka, K., Ono, Y., and Sakakibara, H. (2008). Gene expression and sensitivity in response to copper stress in rice leaves. J. Exp. Bot. 59, 3465-3474. doi: 10.1093/jxb/ern 196

Vardhini, B. V. (2016). "Brassinosteroids are potential ameliorators of heavy metal stresses in plants," in Plant Metal Interaction, ed. P. Ahmad (Amsterdam: Elsevier), 209-237.

Wang, W., Bai, M.-Y., and Wang, Z.-Y. (2014). The brassinosteroid signaling network - a paradigm of signal integration. Curr. Opin. Plant Biol. 21, 147-153. doi: 10.1016/j.pbi.2014.07.012

Xia, X. J., Wang, Y. J., Zhou, Y. H., Tao, Y., Mao, W. H., Shi, K., et al. (2009). Reactive oxygen species are involved in brassinosteroid-induced stress tolerance in cucumber. Plant Physiol. 150, 801-814. doi: 10.1104/pp.109.138230

Yusuf, M., Fariduddin, Q., and Ahmad, A. (2011). 28-Homobrassinolide mitigates boron induced toxicity through enhanced antioxidant system in Vigna radiata plants. Chemosphere 85, 1574-1584. doi: 10.1016/j.chemosphere.2011.08.004

Zhabinskii, V. N., Khripach, N. B., and Khripach, V. A. (2015). Steroid plant hormones: effects outside plant kingdom. Steroids 97, 87-97. doi: 10.1016/j.steroids.2014.08.025

Zhao, B., and Li, J. (2012). Regulation of brassinosteroid biosynthesis and inactivation. J. Integr. Plant Biol. 54, 746-759. doi: 10.1111/j.17447909.2012.01168.x

Conflict of Interest Statement: The authors declare that the research was conducted in the absence of any commercial or financial relationships that could be construed as a potential conflict of interest.

Copyright (c) 2016 Rajewska, Talarek and Bajguz. This is an open-access article distributed under the terms of the Creative Commons Attribution License (CC BY). The use, distribution or reproduction in other forums is permitted, provided the original author(s) or licensor are credited and that the original publication in this journal is cited, in accordance with accepted academic practice. No use, distribution or reproduction is permitted which does not comply with these terms. 